\title{
Biocatalytic Process Design and Reaction Engineering*
}

\author{
R. Wohlgemuth ${ }^{* *}$ \\ Sigma-Aldrich, Member of Merck Group, \\ Industriestrasse 25, CH-9470 Buchs, Switzerland
}

\author{
() (1) \\ This work is licensed under a \\ Creative Commons Attribution 4.0 \\ International License \\ doi: 10.15255/CABEQ.2016.1029 \\ Review \\ Received: November 2, 2016 \\ Accepted: May 31, 2017
}

\begin{abstract}
Biocatalytic processes occurring in nature provide a wealth of inspiration for manufacturing processes with high molecular economy. The molecular and engineering aspects of bioprocesses converting available raw materials into valuable products are therefore of much industrial interest. Modular reaction platforms and straightforward working paths, from the fundamental understanding of biocatalytic systems in nature to the design and reaction engineering of novel biocatalytic processes, have been important for shortening development times. Building on broadly applicable reaction platforms and tools for designing biocatalytic processes and their reaction engineering are key success factors. Process integration and intensification aspects are illustrated with biocatalytic processes to numerous small-molecular weight compounds, which have been prepared by novel and highly selective routes, for applications in the life sciences and biomedical sciences.
\end{abstract}

Key words:

molecular economy, retrosynthetic analysis, route selection, biocatalytic asymmetric synthesis, biocatalysts, biocatalytic process assembly, biocatalytic process prototyping, reaction engineering, process intensification, product recovery

\section{Introduction}

New functional molecular entities and synthetic methodologies, selectivity, resource efficiency and sustainability have been key performance drivers in the design of processes for manufacturing the desired products from adequate starting materials $\mathrm{s}^{1-3}$. While product purity and yield are in the forefront, resource efficiency and sustainability goals need to be met as well, as usually a number of auxiliary reagents and solvents are involved for each reaction and purification step, leading at the end to the accumulation of varying amounts of waste per unit of product manufactured ${ }^{4-6}$. This is measured by the $\mathrm{E}$ factor, which has obtained a lot of attention in basic and industrial process design for assessing the minimization of waste and environmental impact of manufacturing processes over the past 25 years ${ }^{7}$. Waste minimization can be achieved by avoiding the use of auxiliary reagents in stoichiometric quantities, by highly selective reactions which do not lead to side products or follow-up products, and by high degrees of conversion which minimize purification media, auxiliary reagents, and solvent usage in product recovery. Nature provides a blueprint for process design by achieving the enormous tasks

\footnotetext{
*Based on an Invited Keynote Lecture at the CHISA 2016 Congress,

Prague, Czech Republic, August 28-31, 2016

***mail: roland.wohlgemuth@sial.com
}

of complex compound syntheses with high space-, time and stereocontrol. This is due to the great and growing diversity of natural, modified and designed biocatalysts, which have been described, and provide a tremendous knowledge base of renewable and non-toxic catalysts for resource-efficient biotransformations ${ }^{8}$. Biocatalysts are also versatile with respect to solvents as organic synthetic reactions in biological cells can be achieved in aqueous or membrane environments and no organic solvents are needed, thereby putting biocatalysis in an excellent position for a paradigm change of solvent use in organic synthesis 9 . Biocatalysis is therefore ideally suited for applying the concept of molecular economy (Figure 1) to the design of manufacturing processes and the development of a sustainable chemistry ${ }^{10}$. As the resource efficiency goal has been approached in parallel from different perspectives, interfacing chemistry with the biosciences ${ }^{11}$ as well as bridging the molecular with the engineering sciences $^{12}$ is instrumental for successful industrial implementation $^{13}$.

Biocatalytic process design can be inspired from the two extremes of exclusive chemical and biological methodologies. Bottlenecks and limitations in purely chemical manufacturing processes, the needs for selective new tools in total synthesis/ diverted total synthesis and disruptive experiences to the quest that any molecular structure, no matter how complicated, can be constructed by the excel- 


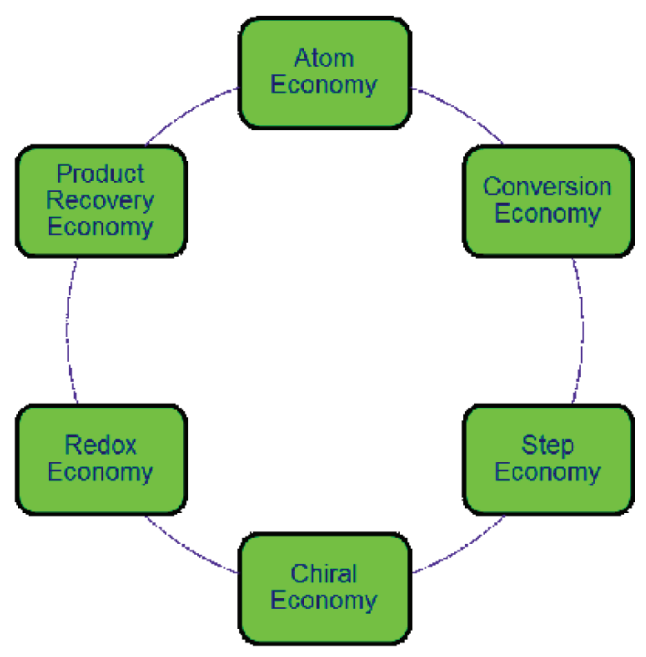

Fig. 1 - Manufacturing performance, selectivity, sustainability by molecular economy

lent tools of organic chemistry, can start the search for enzymes capable of catalyzing a particular reaction not possible with present synthetic methodologies. Metabolism, inhibition, regulation, and transport in purely biological manufacturing processes, arising from the perspective of why you should synthesize a compound yourself if a bug can do for it for you, can, on the other hand, require to rely on robust chemical reactions or to develop new synthetic methods for manufacturing.

From the organic chemistry side, great progress has been achieved in the area of green and sustainable chemistry with a broad range of highly selective and tailor-made biocatalytic transformation types, which are superior to the corresponding tools available, developed for an increasing number of substrates ${ }^{14-15}$. As many biocatalytic reactions have moved successfully from laboratory to industrial scale $^{16-19}$, the interest to consider a biocatalytic reaction step already from the beginning in the design of a chemical manufacturing process as an option for a reaction in a synthetic sequence has been growing ${ }^{20-22}$. From the other extreme of synthesizing a compound by biosynthesis in the fermentation of whole cells, the success of white and industrial biotechnology is due to the tremendous progress in biochemical and metabolic engineering, molecular biology and synthetic biology, which opened options for the design of complete biocatalytic pathways from simple starting materials to complex products ${ }^{23-25}$

Whether the manufacturing route originates from the chemical or the biological methodologies, a number of criteria which are considered in designing the route, are common to both, e.g. the design direction of old routes, with the advantage of building on established technologies or with the option to revitalize it, versus the design of completely new routes with the aim of faster and shorter routes to the target compounds. The route architecture with its related use of reaction space and reaction time like a linear or convergent route, multi-step- or multi-component reaction, offers numerous opportunities for route design ${ }^{10}$. A great advantage of using biocatalysts for performing reaction steps in these routes are their privileged properties, like their chemoselectivity in transforming non-protected substrates and their enantioselectivity due to their inherent chirality. This latter property has been successfully used in biocatalytic reactions for resolving racemic mixtures to pure enantiomers, for desymmetrizing prochiral or symmetric substrates, and for catalytic asymmetric synthesis ${ }^{26-28}$. The design of synthetic routes is not restricted to finding ways how to synthesize a product target from suitable starting materials, but can also be oriented towards an abundant and inexpensive starting material. If this starting material is renewable by nature, constantly accumulated as a side product or as waste in a large-scale manufacturing process, and no further use of these resources than disposal is envisioned, designing new processes improves resource efficiency. It is of increased interest for a number of industrial applications to shift the starting point of manufacturing routes from fossil-based to bio-based raw materials ${ }^{29}$. Whether routes are oriented towards product targets, starting materials, functions, or diversity, biocatalytic process design is a key enabling framework.

\section{Analysis and design tools}

Routes oriented towards starting materials require a forward-looking analysis and the imagination of valuable target products, which could be made accessible from the given starting material, as shown in Figure 2 for the case of glycerol ${ }^{30-31}$. Target product-oriented routes are routinely designed by a retrosynthetic analysis and a decision from which material to start with, as schematically shown in Figure 3. The integration of biocatalysis into classical retrosynthetic analysis is thereby importa$\mathrm{nt}^{32}$ and demonstrated by the cases of the target products enantiomerically pure D- and L-lactaldehydes as well as $\mathrm{KDG}^{33-34}$. Another key prerequisite for successful biocatalytic processes is the availability of adequate and reliable methodologies for bioprocess analysis at the start of development for the unambiguous identification and purity determination of the product. If analytical methods like enzyme assays for a particular bioprocess have not been described previously, their development is instrumental for bioprocess screening and development ${ }^{35}$. Straightforward analytical methodologies for separating products from starting materials and 


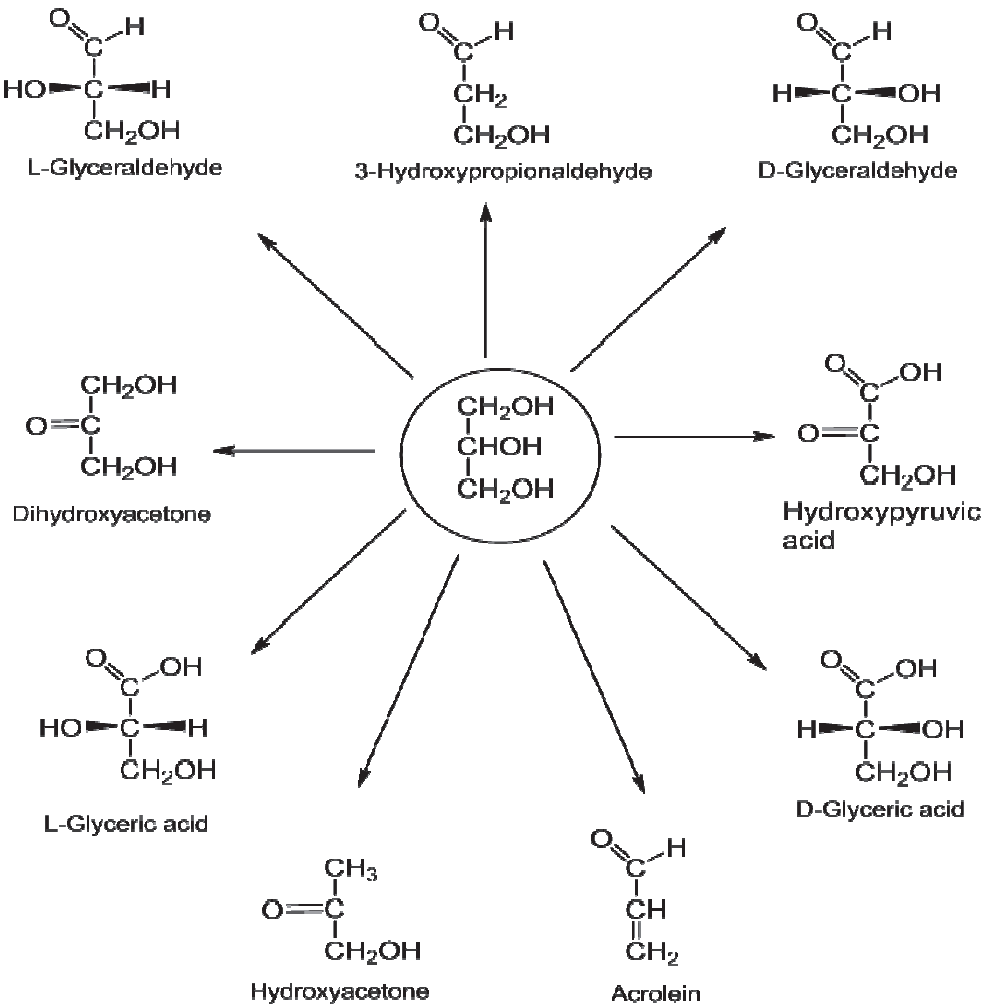

mentation which are integrated into the manufacturing process as analytical in-process controls. PAT is of much interest for a better understanding of the process in development ${ }^{36}$ or for controlling critical unit operations like reactions, workup, crystallization and drying ${ }^{37}$. In the innovative transaminase-catalysed process for manufacturing the sitagliptin $\mathrm{API}^{38}$, the particle size distribution of the API is an important quality specification. As the API particle size is dependent on the seeding point temperature of its crystallization from solution, which itself depends on the solution composition of each batch before crystallization, the analysis of the composition of the solution is important. This has been achieved by NIR spectroscopy of the sitagliptin free base, water, isopropylamine, DMSO and isopropylacetate concentrations in real time prior to the seeding point of sitagliptin crystallization $^{39}$. These real-time NIR measurements not only increased productivity and flexibility, but also enabled the implantation of a control strategy ${ }^{39}$.
Fig. 2 - Starting material-oriented routes to products originating from glycerol

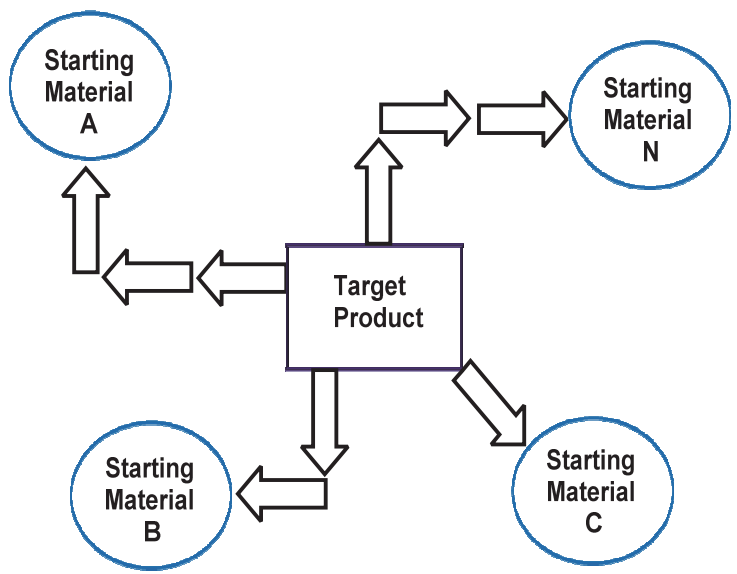

Fig. 3 - Target product-oriented routes

detecting product formation are not only valuable for development, but also for monitoring manufacturing processes. Industrial manufacturing processes demanding consistent batch-to-batch quality within the specifications are ideally developed the first time right with adequate analytical tools in order to achieve the desired quality by designing it from the beginning with the $\mathrm{QbD}$ methodology. This can be achieved by taking discrete samples during the manufacturing process, which are transported to the analytical instruments and analysed off-line or by designing on-line analytical instru-

\section{Biocatalytic process assembly and prototyping}

Biocatalytic reaction platforms with numerous biocatalysts and their applications, established over the years for many reaction classes like reductions ${ }^{40-41}$, oxidations ${ }^{42-44}$, hydrolysis ${ }^{45-46}$, aminations $^{47-48}$ or phosphorylations ${ }^{49-50}$, have paved the way for extending the biocatalyst applications to new substrates and for putting together new synthetic routes. Best practices in the assembly of synthetic biocatalytic as well as chemical synthetic reactions involve rapid prototyping of the most critical reaction steps in order to obtain the first proof-of-principle. It is thereby useful to overcome bottlenecks for single biocatalytic reaction steps, as shown in Figure 4 for selected examples, before proceeding to prototyping the whole sequence. The examples illustrate challenges in biocatalytic process development and different approaches how to tackle them. The synthesis of the pharmaceutical intermediate ethyl-(1R,2R)-2-(3,4-difluorophenyl)cyclopropanecarboxylate to Ticagrelor has been achieved with $79 \%$ yield and very high selectivity by engineering a truncated globin of Bacillus subtilis enzyme, which catalysed the cyclopropanation of 3,4-difluorostyrene with ethyl diazoacetate ${ }^{51}$. Among the many synthetic approaches to the neuraminidase inhibitor oseltamivir phosphate, the route including the enzymatic desymmetrization of a meso-1,3-cyclohexane-dicarboxylic acid diester as the 

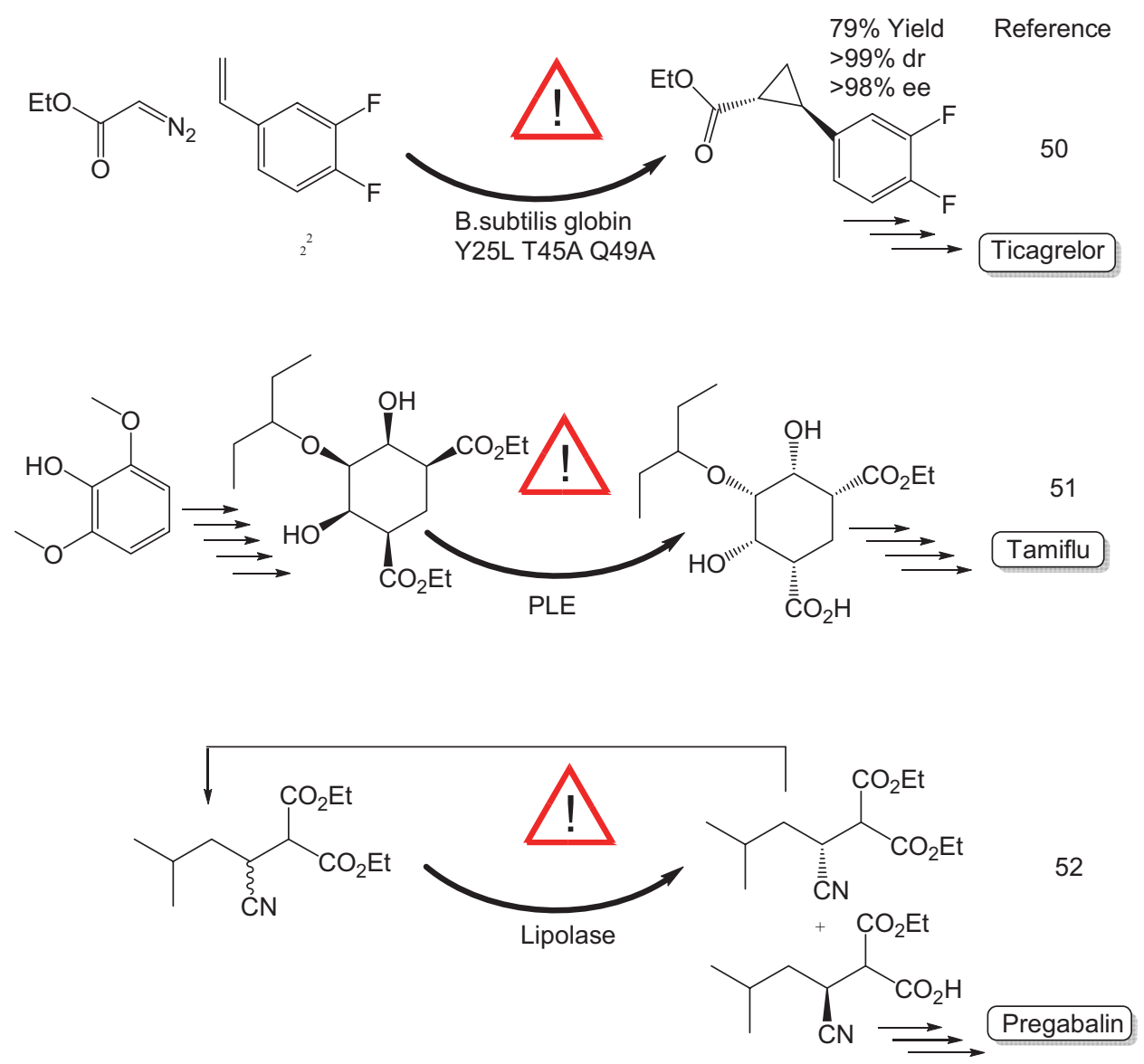

Fig. 4 - Debottlenecking single biocatalytic reactions in synthetic sequences

origin of chirality, enabled not only the synthesis of this anti-influenza drug Tamiflu ${ }^{\circledR}$ from cheap 2,6-dimethoxyphenol in $30 \%$ yield, but also the synthesis of its enantiomer simply by substituting pig liver esterase with a lipase from Aspergillus oryzae $e^{52}$. Lipase-catalysed resolution of rac-2-carboxyethyl-3-cyano-5-methyl-hexanoic acid ethyl ester and subsequent decarboxylation has been a key process improvement in the synthesis of the Pregabalin precursor (S)-3-cyano-5-methylhexanoic acid ethyl es$\operatorname{ter}^{53}$. In the case of the $(S)$ - and $(R)$-lactaldehydes, the identification of the most suitable ketoreductases has been decisive for the key biocatalytic asymmetric reductions of 1,1-dimethoxy-2-propanone to enantiomerically pure (S)- and (R)-1,1-dimethoxy-2-propanols, which have been obtained in $\geq 99.9 \%$ ee and excellent yield ${ }^{33}$. In the case of a one-step route to (R)-mevalonate-5-phosphate, prototyping the kinetic resolution of racemic mevalo-lactone required a recombinant mevalonate kinase and reaction monitoring of the biocatalytic asymmetric phosphorylation by quantitative ${ }^{31} \mathrm{P}-\mathrm{NMR}^{54}$. In the development of a one-step route to KDG, the simultaneous qualitative and quantitative analysis of D-gluconate and 2-keto-3-deoxy-D-gluconate by LC-MS for reaction monitoring and a recombinant gluconate dehydratase enabled the efficient and selective biocatalytic water elimination reaction ${ }^{34}$. The bottleneck in the synthesis of all limonene oxide enantiomers and their corresponding diols has been overcome by the discovery of epoxide hydrolases with complementary stereoselectivity and their recombinant expression in $E$. coli in highly resource-efficient one-step biocatalytic resolutions of $(+)$-cis/trans limonene oxide and $(-)$-cis/trans-limonene oxide ${ }^{55-56}$.

Although biocatalysts have been discovered for an increasing number of reaction types, it is rare that large numbers of different substrates can be converted with high efficiency by the same enzyme. Therefore, the most suitable biocatalyst for the conversion of a given substrate to the desired product usually needs to be discovered, developed or engineered, which requires meaningful, robust and sensitive screening methodologies and can be challenging. In addition, process targets may not be reached by reaction engineering with an otherwise suitable enzyme under the given process boundary conditions, which then again may require further development of the enzyme. There are also many reaction types in organic synthesis, for which catalytic 
asymmetric versions and biocatalysts are not available, which is a disadvantage and needs to be overcome by interfacing biocatalysis with classical organic synthesis ${ }^{11}$.

\section{Reaction engineering}

Reaction rate laws, targets and variable parameters for biocatalytic processes are different from chemocatalytic reactions due to effects of higher substrate and product concentrations, which are desirable to achieve high space-time yields, on the biocatalysts in industrial processes compared to regulated biocatalytic reactions in nature, different tools for shifting thermodynamic equilibria and solvent, temperature and $\mathrm{pH}$ influences on biocatalyst properties ${ }^{57}$. Depending on previous knowledge of the biocatalytic reaction platform, the reaction engineering can work with mathematical optimization tools to define optimum reaction conditions for well-characterized reaction systems, with practical design-of-experiments methodology after prototyping or, if data are lacking, with experimental data acquisition on the characterization of biocatalytic reaction kinetics, biocatalysts, components and thermodynamics of the reaction system as a function of variable parameters ${ }^{49}$. Unfavourable thermodynamics may be overcome by making the reaction irreversible via the utilization of irreversible substrates, different reaction media or the coupling to subsequent irreversible reaction steps. In cases of stability mismatches between substrate or product stabilities and enzyme activities and stabilities, rapid progress can be obtained by optimizing process windows ${ }^{58}$. Further optimization of reaction engineering parameters, such as the degree of conversion, selectivity, and specific productivity, require more work, but can lead to highly efficient synthetic procedures ${ }^{59-60}$. In addition to high space-time yield, reaction engineering and process intensification aim at complete conversion to the final product in order to avoid laborious product isolation operations ${ }^{61-63}$. Even with complete conversion, the final product also needs to be recovered and purified from the reaction system with high efficiency ${ }^{64}$. In a systematic optimization of the biocatalytic reaction system using DoE parameter investigations for the manufacturing of the enantiomerically pure D- and L-lactaldehydes, the reaction engineering target values have been met and even surpassed with $>99 \%$ yield, $>99 \%$ ee at $250 \mathrm{~g} \mathrm{~L}^{-1}$ substrate loading and $0.05 \mathrm{~g} \mathrm{~L}^{-1}$ NADP cofactor requirement, after two phases of process development subsequent to screening ${ }^{33}$. In the case of the biocatalytic resolution of $(+)$-cis/trans limonene oxide and (-)-cis/trans-limonene oxide, the choice of the most suitable reaction parameters, like substrate loading, $\mathrm{pH}$, tem-

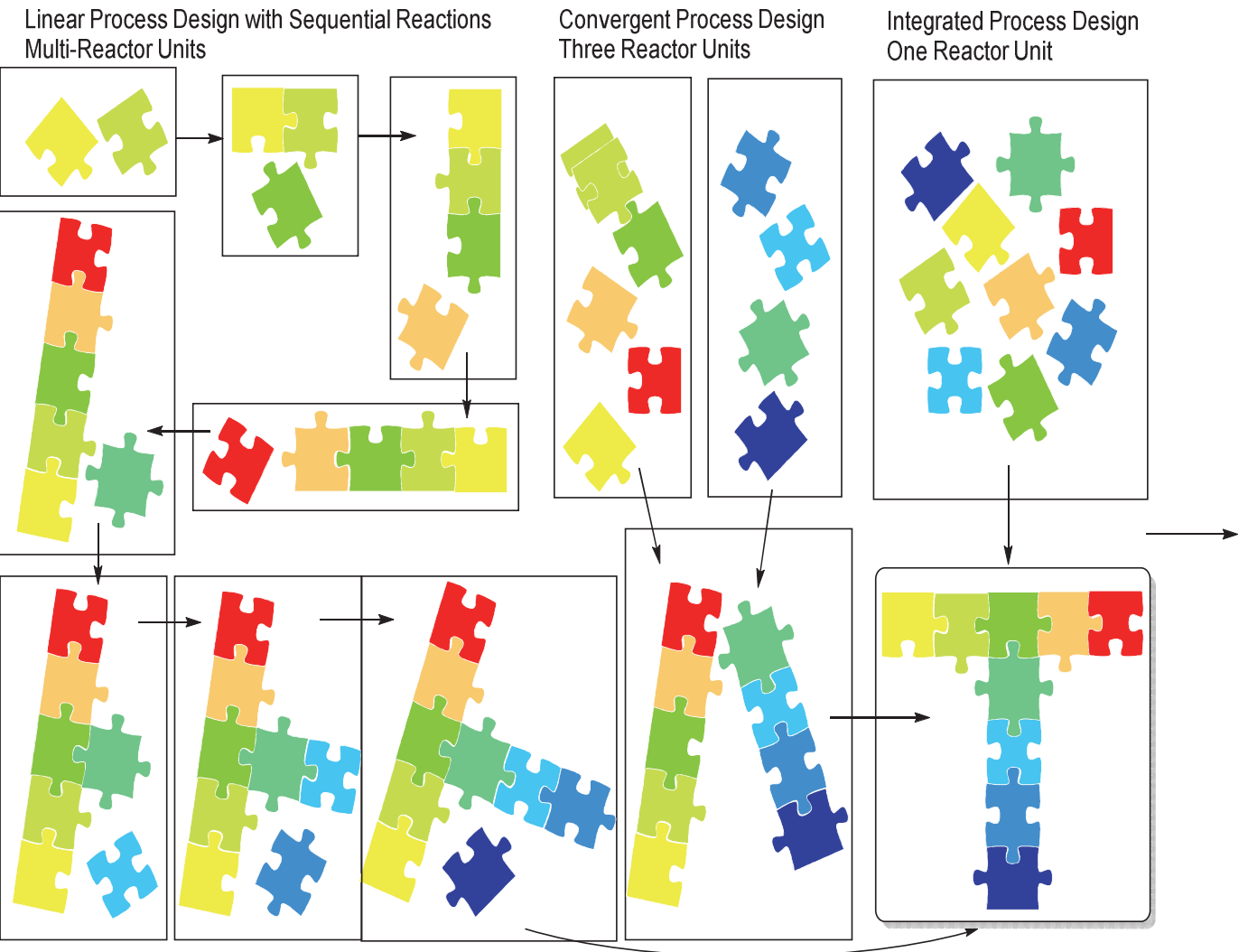

Fig. 5 - Bioinspired biocatalytic process design strategies 
perature and cosolvents, was based on experimental investigations of limonene oxide stability, epoxide hydrolase stability and activity as a function of $\mathrm{pH}$ and temperature $\mathrm{e}^{5-56}$. The optimization of the reaction conditions for these epoxide hydrolase-catalysed resolutions has led to improved space-time yields and specific productivities with up to $2 \mathrm{M}$ substrate concentrations and lower enzyme consumption numbers, without the need for cosolvents $^{56}$.

\section{Outlook}

The design of new biocatalytic routes to compounds which have not been accessible up to now or had to be manufactured over a multitude of reaction steps with low yields is an attractive and powerful option. With the rapid and versatile technologies of molecular biology and protein expression novel straightforward biocatalytic routes to such products can be designed by taking advantage of nature's established reaction types, such as biocatalytic phosphorylations, like the biocatalytic phosphorylation of L-arginine to $\mathrm{N}_{-}$-phospho-L-arginine ${ }^{65}$ or the glycerate-2-kinase-catalyzed synthesis of D-glycerate 2-phosphate ${ }^{66}$. This enables the extension of biocatalytic process design towards a) reactions with new substrates and enzymes within established biocatalytic reaction platforms, and b) the development of novel biocatalytic reaction platforms. Screening for suitable biocatalysts, substrates and reaction conditions represents significant research efforts, and automation of the workflow can accelerate the development ${ }^{67}$. Microscale technologies offer thereby strategic advantages for the development and realization of biocatalytic processes and subsequent product recovery steps ${ }^{68}$. Reaction engineering for biocatalytic processes in flow is flexible and simplified, since the developed processes can be parallelized or scaled out instead of the classical scale-up procedure in going from small-scale to large-scale manufacturing. In both batch and flow systems, biocatalytic process intensification and the construction of coupled reactions steps all together in one unit or sequentially in two or more units, depending on compatibilities, is of much interest. This biocatalytic process design (Figure 5) follows nature and is attractive, since purification of intermediates can be avoided. Thermodynamic limitations can be overcome by coupling unfavourable reactions with subsequent irreversible reactions. Finally, side reactions may be prevented as biocatalytic reactions are likely to be orthogonal, of course to be verified experimentally. The times are changing towards biocatalytic process design and reaction engineering.

\section{References}

1. Wender, P. A., Miller, B. L., Synthesis at the molecular frontier, Nature 460 (2009) 197. doi: https://doi.org/10.1038/460197a

2. Gaich, T., Baran, P. S., Aiming for the ideal synthesis, J. Org. Chem. 75 (2010) 4657. doi: https://doi.org/10.1021/jo1006812

3. Walsh, C. T., Fischbach, M. A., Natural products version 2.0: Connecting genes to molecules, J. Am. Chem. Soc. 132 (2010) 2469.

doi: https://doi.org/10.1021/ja909118a

4. Sheldon, R. A., Organic synthesis-past, present and future, Chemistry and Industry 23 (1992) 903.

5. Wohlgemuth, R., Green Production of Fine Chemicals by Isolated Enzymes, in: Tao, J., Kazlauskas, R. (Eds.), Biocatalysis for Green Chemistry and Process Development, John Wiley \& Sons, Inc., Hoboken, New Jersey, 2011, pp 277-298.

6. $L i$, C. J., Exploration of new chemical reactivities for sustainable molecular transformations, Chem. 1 (2016) 423. doi: https://doi.org/10.1016/j.chempr.2016.08.007

7. Sheldon, $R$. A., The E factor 25 years on: the rise of green chemistry and sustainability, Green Chem. doi: https://doi.org/10.1039/C6GC02157C

8. Placzek, S., Schomburg, I., Chang, A., Jeske, L., Ulbrich, M., Tillack, J., Schomburg, D., BRENDA in 2017: new perspectives and new tools in BRENDA, Nucl. Acids Res. first published online October 19, 2016. doi: https://doi.org/10.1093/nar/gkw952

9. Lipshutz, B. H., Gallou, F., Handa, S., Evolution of Solvents in Organic Chemistry, ACS Sustainable Chem. Eng. doi: https://doi.org/10.1021/acssuschemeng.6b01810

10. Wohlgemuth, R., Biocatalysis - key to sustainable industrial chemistry, Current Opin. Biotechnol. 21 (2010) 713.

11. Wohlgemuth, R., Interfacing biocatalysis and organic synthesis, J. Chem. Technol. Biotech. 82 (2007) 1055.

12. Wohlgemuth, R., Molecular and engineering perspectives of the biocatalysis interface to chemical synthesis, Chem. Biochem. Eng. Quarterly 25 (2011) 125.

13. Schmid, A., Dordick, J. S., Hauer, B., Kiener, A., Wubbolts, $M$., Witholt, $B$., Industrial biocatalysis today and tomorrow, Nature 409 (2001) 258. doi: https://doi.org/10.1038/35051736

14. Faber, K., Fessner, W. D., Turner, N. J., Science of Synthesis: Biocatalysis in Organic Synthesis, Vol. 1-3, Georg Thieme Verlag KG, Stuttgart, 2015. 
15. Bornscheuer, U. T., Huisman, G. W., Kazlauskas, R. J., Lutz, S., Moore, J. C., Robins, K., Engineering the third wave of biocatalysis, Nature 485 (2012) 185. doi: https://doi.org/10.1038/nature11117

16. Liese, A., Seelbach, K., Wandrey, C., Industrial biotransformations, John Wiley \& Sons, 2006.

17. Meyer, H. P., Eichhorn, E., Hanlon, S., Lütz, S., Schürmann, M., Wohlgemuth, R., Coppolecchia, R., The use of enzymes in organic synthesis and the life sciences: Perspectives from the Swiss Industrial Biocatalysis Consortium (SIBC), Cat. Sci. Technol. 3 (2013) 29.

18. Ghisalba, O., Meyer, H. P., Wohlgemuth, R., Industrial Biotransformation, in: Encyclopedia of Industrial Biotechnology, Flickinger, M. C., (Ed.), Wiley, Hoboken, NJ, 2010, pp $1-34$.

19. Franssen, M. C. R., Kircher, M., Wohlgemuth, R., Industrial Biotechnology in the Chemical and Pharmaceutical Industries, in: Industrial Biotechnology, Sustainable Growth and Economic Success, Soetaert, W., Vandamme, E. J. (Eds.) Wiley-VCH, Weinheim, 2010, pp 323-350.

20. Reetz, M. T., Biocatalysis in organic chemistry and biotechnology: past, present, and Future, J. Am. Chem. Soc. 135 (2013) 12480 doi: https://doi.org/10.1021/ja405051f

21. Clouthier, C. M., Pelletier, J. N., Expanding the organic toolbox: a guide to integrating biocatalysis in synthesis, Chem. Soc. Rev. 41 (2012) 1585. doi: https://doi.org/10.1039/c2cs15286j

22. Nestl, B. M., Hammer, S. C., Nebel, B. A., Hauer, B., New generation of biocatalysts for organic synthesis, Angew. Chem. Int. Ed. 53 (2014) 3070. doi: https://doi.org/10.1002/anie.201302195

23. Nielsen, J., Keasling, J. D., Engineering cellular metabolism, Cell 164 (2016) 1185. doi: https://doi.org/10.1016/j.cell.2016.02.004

24. Lee, J. W., Na, D., Park, J. M., Lee, J., Choi, S., Lee, S. Y., Systems metabolic engineering of microorganisms for natural and non-natural chemicals, Nature Chem. Biol. 8 (2012) 536.

25. Stephanopoulos, G., Synthetic biology and metabolic engineering, ACS Synth. Biol. 1 (2012) 514.

26. Wohlgemuth, R., Asymmetric biocatalysis with microbial enzymes and cells, Current Opin. Microbiol. 13 (2010) 283.

27. García-Urdiales, E., Alfonso, I., Gotor, V., Enantioselective enzymatic desymmetrizations in organic synthesis, Chem. Rev. 105 (2005) 313. doi: https://doi.org/10.1021/cr040640a

28. Gotor, V., Alfonso, I., García-Urdiales, E. (Eds.), Asymmetric Organic Synthesis with Enzymes, John Wiley \& Sons, 2008.

29. Wohlgemuth, R., The locks and keys to industrial biotechnology, New Biotechnol. 26 (2009) 204.

30. Richter, N., Neumann, M., Liese, A., Wohlgemuth, R. Eggert, T., Hummel, W., ChemBioChem 10 (2009) 1888.

31. Richter, N., Neumann, M., Liese, A., Wohlgemuth, R., Weckbecker, A., Eggert, T., Hummel, W., Biotech. Bioeng. 106 (2010) 541. doi: https://doi.org/10.1002/bit.22714

32. Turner, N. J., O'Reilly, E., Biocatalytic retrosynthesis, Nature Chem. Biol. 9 (5) (2013) 285.

33. Vogel, M. A. K., Burger, H., Schläger, N., Meier, R. Schönenberger, B., Bisschops, T., Wohlgemuth, R., Highly efficient and scalable chemoenzymatic syntheses of (R)and (S)-lactaldehydes, Reaction Chem. Eng. 1 (2016) 156. doi: https://doi.org/10.1039/C5RE00009B
34. Matsubara, K., Köhling, R., Schönenberger, B., Kouril, T., Esser, D., Bräsen, C., Siebers, B., Wohlgemuth, R., Onestep synthesis of 2-keto-3-deoxy-D-gluconate by biocatalytic dehydration of D-gluconate, J. Biotechnol. 191 (2014) 69. doi: https://doi.org/10.1016/j.jbiotec.2014.06.005

35. Reymond, J. L., Enzyme Assays, John Wiley \& Sons, 2006.

36. Chanda, A., Daly, A. M., Foley, D. A., LaPack, M. A., Mukherjee, S., Orr, J. D., Reid III, G. L., Thompson, D. R., Ward II, $H$. W., Industry perspectives on process analytical technology: Tools and applications in API development, Org. Process Res. Dev. 19 (2015) 63. doi: https://doi.org/10.1021/op400358b

37. Bordawekar, S., Chanda, A., Daly, A. M., Garrett, A. W., Higgins, J. P., LaPack, M. A., Maloney, T. D., Morgado, J., Mukherjee, S., Orr, J. D., Reid III, G. L., Yang, B. S., Ward $I I, H$. W., Industry perspectives on process analytical technology: Tools and applications in API manufacturing, Org. Process Res. Dev. 19 (2015) 1174. doi: https://doi.org/10.1021/acs.oprd.5b00088

38. Savile, C. K., Janey, J. M., Mundorff, E. C., Moore, J. C., Tam, S., Jarvis, W. R., Colbeck, J. C., Krebber, A., Fleitz, F. J., Brands, J., Devine, P. N., Huisman, G. W., Hughes, G. $J$., Biocatalytic asymmetric synthesis of chiral amines from ketones applied to sitagliptin manufacture, Science 329 (2019) 305.

39. Zhou, G., Grosser, S., Sun, L., Graffius, G., Prasad, G., Moment, A., Spartalis, A., Fernandez, P., Higgins, J., Wabuyele, B., Starbuck, C., Application of on-line NIR for process control during the manufacture of sitagliptin, Org. Process Res. Dev. 20 (2016) 653.

40. Ni, Y., Xu, J. H., Biocatalytic ketone reduction: a green and efficient access to enantiopure alcohols, Biotechnol. Adv. 30(6) (2012) 1279.

41. Wohlgemuth, R., Development of Sustainable Biocatalytic Reduction Processes for Organic Chemists, in: Brenna, E (Ed.), Synthetic Methods for Biologically Active Molecules: Exploring the Potential of Bioreductions, Wiley-VCH, Weinheim, 2014, pp. 1-25.

42. Hollmann, F., Arends, I. W., Buehler, K., Schallmey, A., Bühler, B., Enzyme-mediated oxidations for the chemist, Green Chem. 13 (2011) 226. doi: https://doi.org/10.1039/C0GC00595A

43. Wohlgemuth, R., Biocatalytic asymmetric oxidation, in: Modern Biocatalysis, Fessner, W. D., Anthonsen, T. (Eds.), Wiley-VCH, Weinheim, 2009, pp. 313-338.

44. Wohlgemuth, R., Oxidation by Microbial Methods, in: Comprehensive Organic Synthesis II, Molander, G., Knochel, $P$. (Eds.), Volume 7, 2nd Edition, Elsevier, pp.121-144.

45. Bornscheuer, U. T., Kazlauskas, R. J., Hydrolases in organic synthesis: regio- and stereoselective biotransformations, John Wiley \& Sons, 2006.

46. Wohlgemuth, R., in: Large-Scale Asymmetric Catalysis, Blaser, H. U., Federsel, H. J. (Eds.), Wiley-VCH, Weinheim, 2010, pp 249-264.

47. Brundiek, H., Höhne, M., Transaminases-A Biosynthetic Route for Chiral Amines, in: Applied Biocatalysis - From Fundamental Science to Industrial Applications, Liese, A., Hilterhaus, L., Kettling, U., Antranikian, G. (Eds.), Wiley-VCH, 2016, pp.199-218.

48. Ward, J., Wohlgemuth, R., High-yield biocatalytic amination reactions in organic Synthesis, Curr. Org. Chem. 14 (2010) 1914 doi: https://doi.org/10.2174/138527210792927546

49. Gauss, D., Schoenenberger, B., Molla, G. S., Kinfu, B. M., Chow, J., Liese, A., Streit, W., Wohlgemuth, R., in: Applied Biocatalysis - From Fundamental Science to Industrial Applications, Liese, A., Hilterhaus, L., Kettling, U., Antranikian, G. (Eds.), Wiley-VCH, Weinheim, 2016, pp. 147-177. 
50. Wohlgemuth, R., Liese, A., Streit, W., Biocatalytic phosphorylations of metabolites: Past, present, and future, Trends in Biotechnology 35 (2017) 452.

51. Hernandez, K. E., Renata, H., Lewis, R. D., Kan, S. B. J., Zhang, C., Forte, J., Rozzell, D., McIntosh, J. A., Arnold, F. $A$., Highly stereoselective biocatalytic synthesis of key cyclopropane intermediate to ticagrelor, ACS Catal. 6 (2016) 7810 .

doi: https://doi.org/10.1021/acscatal.6b02550

52. Zutter, U., Iding, H., Spurr, P., Wirz, B., New, efficient synthesis of oseltamir phosphate (Tamiflu) via enzymatic desymmetrization of a meso-1,3-cyclohexanedicarboxylic acid diester, J. Org. Chem. 73 (2008) 4895. doi: https://doi.org/10.1021/jo800264d

53. Martinez, C. A., Hu, S., Dumond, Y., Tao, J., Kelleher, P., Tully, L., Development of a chemoenzymatic manufacturing process for pregabalin, Org. Proc. Res. Dev. 12 (2008) 392.

54. Matsumi, R., Hellriegel, C., Schoenenberger, B., Milesi, T., van der Oost, J., Wohlgemuth, R., Biocatalytic asymmetric phosphorylation of mevalonate, RSC Adv. 4 (2014) 12989.

55. Ferrandi, E. E., Sayer, C., Isupov, M. N., Annovazzi, C., Marchesi, C., Iacobone, G., Peng, X., Bonch-Osmolovskaya, E., Wohlgemuth, R., Littlechild, J. A., Monti, D., Discovery and characterization of thermophilic limonene-1,2-epoxide hydrolases from hot spring metagenomic libraries, FEBS J. 282 (2015) 2879. doi: https://doi.org/10.1111/febs.13328

56. Ferrandi, E. E., Marchesi, C., Annovazzi, C., Riva, S., Mon$t i, D$., Wohlgemuth, $R$., Efficient epoxide hydrolase catalyzed resolutions of $(+)$ - and ( $(-)$-cis/trans-limonene oxides, ChemCatChem 7 (2015) 3171.

57. Ringborg, R. H., Woodley, J. M., The application of reaction engineering to biocatalysis, Reaction Chem. Eng. 1 (2016) 10.

58. Gauss, D., Schoenenberger, B., Wohlgemuth, R., Chemical and enzymatic methodologies for the synthesis of enantiomerically pure glyceraldehyde 3-phosphates, Carbohydr. Res. 389 (2014) 18.

59. Molla, G. S., Wohlgemuth, R., Liese, A., One-pot enzymatic reaction sequence for the syntheses of D-glyceraldehyde 3-phosphate and L-glycerol 3-phosphate, J. Mol. Catal. B: Enzymatic 124 (2016) 77.

doi: https://doi.org/10.1016/j.molcatb.2015.12.004
60. Molla, G. S., Kinfu, B. M., Chow, J., Streit, W., Wohlgemuth, R., Liese, A., Bioreaction engineering leading to efficient synthesis of L-glyceraldehyd-3-phosphate, Biotechnol. J. 12 (2017)

doi: https://doi.org/10.1002/biot.201600625

61. Hilker, I., Wohlgemuth, R., Alphand, V., Furstoss, R., Microbial transformations 59: First kilogram scale asymmetric microbial Baeyer-Villiger oxidation with optimized productivity using a resin-based in situ SFPR strategy, Biotech. Bioeng. 92 (2005) 702.

62. Baldwin, C. V. F., Wohlgemuth, R., Woodley, J. M., The first 200-L scale asymmetric Baeyer-Villiger oxidation using a whole-cell biocatalyst, Org. Proc. Res. Dev. 12 (2008) 660.

63. Hilker, I., Baldwin, C., Alphand, V., Furstoss, R., Woodley, $J$. M., Wohlgemuth, R., On the influence of oxygen and cell concentration in an SFPR whole cell biocatalytic BaeyerVilliger oxidation process, Biotech. Bioeng. 93 (2006) 1138 . doi: https://doi.org/10.1002/bit.20829

64. Wohlgemuth, R., Product Recovery, in: Comprehensive Biotechnology, Moo-Young, M., Butler, M., Webb, C., Moreira, A., Grodzinski, B., Cui, Z. F., Agathos, S. (Eds.), $2^{\text {nd }}$ edition, Academic Press, 2011, pp. 591-601.

65. Schoenenberger, B., Wszolek, A., Milesi, T., Obkircher, M., Brundiek, H., Wohlgemuth, R., Synthesis of $\mathrm{N}_{\omega}$-phospho-L-arginine by biocatalytic phosphorylation of L-arginine, ChemCatChem 9 (2017) 121.

66. Hardt, N., Kinfu, B. M., Chow, J., Streit, W. R., Schoenenberger, B., Obkircher, M., Wohlgemuth, R., Biocatalytic asymmetric phosphorylation catalyzed by recombinant glycerate-2-kinase, ChemBioChem (2017). doi: https://doi.org/10.1002/cbic.201700201

67. Dörr, M. D., Fibinger, M. P. C., Last, D., Schmidt, S., Santos-Aberturas, J., Böttcher, D., Hummel, A., Vickers, C., Voss, M., Bornscheuer, U. T., Fully automatized high-throughput enzyme library screening using a robotic platform, Biotechnol. Bioeng. 113 (2016) 1421.

68. Wohlgemuth, R., Plazl, I., Žnidaršič-Plazl, P., Gernaey, K. V., Woodley, J. M., Microscale technology and biocatalytic processes: opportunities and challenges for synthesis, Trends Biotechnol. 33 (2015) 302. 